\title{
Research on the Competency Model for Tourism Management Undergraduates
}

\author{
Mu Zhang \\ Shenzhen Tourism College \\ Jinan University \\ Shenzhen, China
}

\author{
Jiao Li \\ School of Management \\ Sun Yat-sen University \\ Guangzhou, China
}

\author{
Baoqin Huang \\ Corresponding author \\ Shenzhen Tourism College \\ Jinan University \\ Shenzhen, China
}

\begin{abstract}
With the rapid development of China's tourism industry, the domestic education of tourism management major came into being. However, the comprehensiveness and complexity of tourism management education resulted in significant competency differences among the students, leading to serious dislocation of school-enterprise talent supply and demand. This study selected tourism management undergraduates (TMU) as its subjects, combined the results of literature research and questionnaire survey, established a preliminary competency model for TMU through status and factor analyses, and extracted four main factors of the competency model: physical and mental quality, character and moral, science attainment, and professional qualities. Based on the proposed model, the authors brought forward some comments and suggestions for tourism management education.
\end{abstract}

Keywords-tourism management; competency; competency model

\section{INTRODUCTION}

With the rapid development of China's economy, Chinese people have displayed stronger initiative and enthusiasm in spiritual and cultural pursuit, which has hastened the development of tourism industry, making China the $3^{\text {rd }}$ largest tourism state in the world. China's tourism industry has become an important support to its domestic service industry. According to the statistics from the National Tourism Administration (NTA), domestic tourists reached 2.103, 2.641, 2.957 and 3.262 billion respectively from 2010 to 2013, and inbound tourists remained at about 130 million people.

In contrast with the booming domestic tourism industry, TMU are faced with a tough job market-low professional barriers, easy accessibility, a large student body versus limited jobs and so on. According to the statistics of the NTA, in 2013, 544 ordinary institutions of higher learning opened tourism management undergraduate program and 1067 opened the three-year program of tourism specialty, and about 1000 secondary vocational schools had tourism related majors.
Domestic tourism education has presented a trend of prosperity, and the NTA has complemented and perfected the development requirements for higher tourism education. However, the educational scale and investment have encountered disproportional talent output and employment status. In 2014, the National Ministry of Education issued the rankings of 15 low employment undergraduate majors, and Tourism Management was on the list. What are the reasons?

The realities are that tourism management is a major of comprehensiveness. Although it has a diversified curriculum, the knowledge depth of the students needs further enhancement Secondly, its curriculum mode needs adjustment and optimization for short of practical operation training. Thirdly, its talent training objective is not fully in accordance with the talent demand standard of the industry as a result of insufficient effective communications between the schools and the enterprises. Above all things, the key to the problem is to have a thorough understanding of the competency features of tourism management students.

This study aims at providing theoretical and practical support to tourism management program of higher education through establishing a competency model for students majoring in the program.

\section{LITERATURE REVIEW}

Many countries now set up feasible performance measurable indicators according to the competency model of a specific post, with which they appraise the performance of their employees.

In 1970, American Management Association (AMA) launched its first large scale competency model research. In 1973, David McClelland proposed an appraisal principle based on competency attributes ${ }^{[1]}$. In their researches, scholars Peerasit Patanakula and Dragan Milosevicb probed into the basic abilities one must possess in order to accomplish work and the direct factors that can affect job performance ${ }^{[2]}$. 
Lyle Spencer redefined "quality" and presented the "Iceberg Model of Qualities" from attribute perspective, believing that there were two major categories of qualities, dominant and recessive qualities ${ }^{[3]}$.

Management scientist Mansfield reduced job competency to four aspects: skills, emergency handling, relational processing and environment capacity ${ }^{[4]}$. Later researchers followed the above mentioned scholars in their interpretations and investigations of the competency model.

In China, competency model mainly draws on the experience of foreign related research productions. Scholar Jianfeng Peng introduced competency model to China and further developed and promoted it. The earliest researches occurred in 2003, raising concerns both from the scholars and the enterprises.

In the book Design of Employee Competency Model, Jianfeng Peng and Xiaojuan Jing expounded the significance and value of employees' competency on the improvement of human resource management benefits and the establishment and maintenance of core-competitiveness. Moreover, they systematically introduced the procedures and methods of competency model establishment ${ }^{5]}$.

In addition, Professors Kan Shi and Chongming Wang also promoted domestic study of competency model ${ }^{[6] 7]}$. Through research, Qinxuan $\mathrm{Gu}$ and $\mathrm{Mu} \mathrm{Zhu}$ summarized 13 major components of the competency model for human resource personnel: analysis ability, problem solving ability, communication ability, self-control and stress tolerance ${ }^{[8]}$. Ningyu Tang and Xiaoyun Li from Shanghai Jiao Tong University made a comparative analysis of individual's competency and organization's competency, and unearthed the potential connection between them ${ }^{[9]}$.

With the deepening of theoretical research, the application of competency model began to spread. Since 2005, famous domestic enterprises such as Huawei and Unilever began inviting consultant firms to design competency models for their employees, which were used to coach their human resource work. As competency model application gets more and more mature and extensive, government sectors gradually apply this model to their human resource management.

From the above literature review, we can see that competency model research has transited from theory to practice. Most of the existing researches of competency model application explored and answered the question of "what type of talents the enterprises ask for" from an enterprise perspective. However, this study chooses TMU as the subject and probes into the issue of what competency attributes they should possess so as to meet the needs of the enterprises.

\section{THEORETICAL BASIS AND THE COMPONENTS OF COMPETENCY MODEL DESIGN}

\section{A. Definition and Inscape of Competency}

In 1973, McClelland published an article entitled "testing for competency rather than intelligence", in which he pointed out that "it's questionable and unreasonable to judge one's ability by using intelligence test indiscriminately", thus starting the exploration of personal qualities and behavior characteristic factors that may determine and influence one's job performance. In the same year, he raised the word "competency", pointing out that competency is the personal qualities and behavior characteristics that have direct impact on one's job performance.

Dr. McClelland is the founder of competency idea. Through first-hand materials and regression analyses, he defined competency from five aspects: knowledge, technical ability, concept of the self, idiosyncrasy (personality and character) and motivation as following "Table I".

TABLE I. MCCLELLAND’s FIVE-LEVEL COMPETENCY MODEL

\begin{tabular}{|c|l|}
\hline $\begin{array}{c}\text { Knowled } \\
\text { ge }\end{array}$ & Factual and experimental knowledge of a certain field \\
\hline $\begin{array}{c}\text { Technica } \\
\text { l ability }\end{array}$ & $\begin{array}{l}\text { Ability to accomplish a task by structured application of the } \\
\text { acquired knowledge }\end{array}$ \\
\hline $\begin{array}{c}\text { Concept } \\
\text { of the } \\
\text { self }\end{array}$ & Self understanding \\
\hline $\begin{array}{c}\text { Idiosync } \\
\text { rasy }\end{array}$ & $\begin{array}{l}\text { Essential traits and behavior characteristics shown at the } \\
\text { environment and other factors }\end{array}$ \\
\hline $\begin{array}{c}\text { Motivati } \\
\text { on }\end{array}$ & Internal driving force to satisfy one's own needs \\
\hline
\end{tabular}

The famous consultant firm HAY proposed the Iceberg Model of Competency. This model divided the six major factors of competency into dominant competency and recessive competency, and pointed out that recessive competency is the key to discern personal values.

\section{B. Definition and Features of Competency Model}

According to the often cited definition from Jianfeng Peng's book Design of Employee Competency Model, competency model is defined as "a group of different quality elements required of people who want to do a job or reach a certain level of job performance, including different motivational performance, personality and quality requirements self-image and social role characteristics, as well as levels of knowledge and skills. Competency model exists based upon competency and has competency as its basis.

Competency model has the following features:

- Domain. This feature manifests the general requirements of the basic abilities from the industry point of view, including students' knowledge and skills, which vary according to industries.

- Enterprise. This feature shows the individual differences between businesses of the same industry. Different enterprises may have different requirements for their employees in competency quality and behavior because of their unique corporate cultures, management modes and development goals.

- Periodicity. This feature reflects the changeability of an industry or an enterprise. Since competency model is based on the requirements of an industry or an enterprise, it must adapt to the development trend of the industry so as to exert its discretion effect. Thus competency model possesses the feature of periodicity. 


\section{BUILDING OF THE COMPETENCY MODEL FOR TMU}

\section{A. Hypotheses}

This study attempts to establish a competency model for TMU by synthesizing viewpoints of the three parties of schools, enterprises and students. The hypotheses for the model construction are as follows:

1) Hypothesis one: Different tourism enterprises have their competency requirements for TMU. Teachers of higher education have their objectives for cultivating TMU. And the students themselves have their own understanding of what competency qualities they should possess. These three cognitions are highly correlated.

2) Hypothesis two: Under certain circumstances and within a given time frame, cognition of the competency requirements from the three parties is constant.

3) Hypothesis three: The dominant and recessive competency qualities from the three parties can all be clearly defined and described.

\section{B. Research Subjects}

This study chooses three groups of people as its subjects. All of them are closely related to the competency cultivation of TMU: TMU themselves, college teachers and tourism enterprises. Through questionnaire survey of the three parties, the authors learn about and study the competency qualities TMU are expected to possess, and build a competency model based on the research findings.

\section{Questionnaire}

The design of the questionnaire starts with the exploration of the feature words of competency. At websites such as CNKI, China Net, Academic Paper Network, Google, etc., the authors respectively put in "quality", "ability", "feature" and the like as subject, title, key word or abstract to search through related periodical and academic paper retrievals to obtain words related to competency features, and record and add up their meanings and the frequency of their occurrences. They then screen the resulting feature words and obtain the first 28 ability and quality characteristics, with which they design the Questionnaire of Competency Feature Phrases for TMU.

\section{Sample Statistical Analysis}

The survey was conducted both on line and off line. Altogether 181 copies were distributed and collected off line, out of which 167 are valid and 14 invalid. 118 copies were sent out and collected on line, out of which 106 are valid and 12 invalid, adding up to a total of 299 copies with 273 valid ones and 26 invalid ones.

Among the subjects, 133 are males and 140 females, accounting for $48.7 \%$ and $51.3 \%$. Due to some constraints, there are more student subjects, totaling 132 whereas the numbers of college teachers and business management personnel are 71 and 70 respectively.

\section{E. Analyses of Sample Credibility and Validity}

SPSS19.0 software is applied in analyzing the reliability of the gathered data. The result is as following "Table II":

\section{TABLE II. CREDIBILITY STATISTICS}

\begin{tabular}{|c|c|}
\hline Cronbach's Alpha & Number \\
\hline .919 & 28 \\
\hline
\end{tabular}

The above table shows that the Cronbach's Alpha of the 28 items of the competency feature phrase survey is 0.919 . Thus the credibility is rather high.

Validity is effectiveness, which is divided into content validity, criterion validity and construct validity. Since most of the feature phrases are based on previous tested research findings, the content and criterion validities of this study are deemed to meet the requirements. The authors will analyze the construct validity.

A factor analysis is often applied in evaluating construct validity. Before factor analysis, KMO (Kaiser-Meyer-Olkin) sample fitness measurement and Bartlett's Test of Sphericity need to be done to decide whether the tested questionnaire is fit for factor analysis. KMO is to test the simple correlation and partial correlation among the variables. When the result is bigger than 0.8 , it means the effect of factor analysis is good.

SPSS19.0 is used to test KMO and Bartlett's Test of Sphericity of the data. The result is as followimg "Table III":

TABLE III. KMO AND BARTLETT'S TEST

\begin{tabular}{|c|c|l|}
\hline \multicolumn{2}{|c|}{$\begin{array}{c}\text { Kaiser-Meyer-Olkin measure of sampling } \\
\text { sufficient degree }\end{array}$} & 879 \\
\hline \multirow{2}{*}{$\begin{array}{c}\text { Bartlett's Test of } \\
\text { Sphericity }\end{array}$} & Approximate chi square & 1949.617 \\
\cline { 2 - 3 } & $\boldsymbol{d f}$ & 378 \\
\cline { 2 - 3 } & Sig. & .000 \\
\hline
\end{tabular}

The table shows that the KMO value of this survey is 0.879 , bigger than 0.8, and the significance level of Bartlett's Test of Sphericity is 0 , showing that there exists a correlated relationship among all the variables. In other words, this questionnaire is fit for factor analyses.

\section{F. Factor Analyses}

SPSS19.0 software is used in factor analyses so as for the authors to study the appropriateness of the competency features of TMU from the perspectives of the students, the teachers and the management personnel.

The maximum variance method in orthogonal rotation is adopted in factor rotation. The cumulative contribution rate of the three factors is $82.832 \%$ for the student group, $77.16 \%$ for the teacher group and $80.364 \%$ for the management personnel group.

\section{G. Construction of the Model}

According to the factor analyses of the questionnaire, this study attempts to construct the competency model from the three angles of student-teacher-enterprise, finding that out of the 28 competency features decided on earlier, 16 features reflect TMU' quality characteristics in four aspects. They are physical and mental qualities, character and moral, science attainment and professional qualities, based on which the authors establish the competency model for TMU "Fig. 1". 


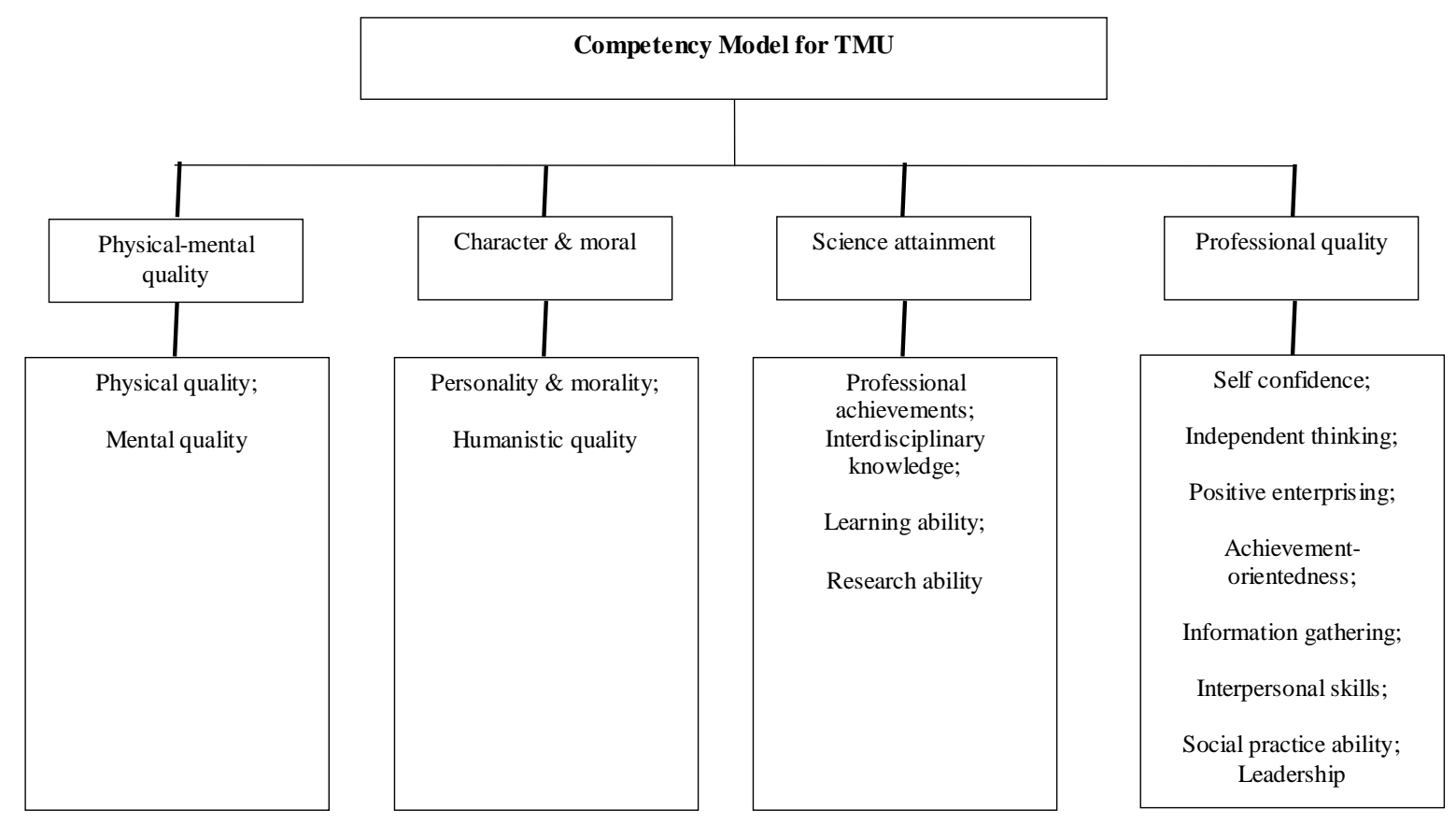

Fig. 1. Competency model for TMU-preliminary model.

\section{ANALYSES AND DisCUSSION}

\section{A. Major Research Findings}

The competency model shows that physical and mental quality is a prerequisite for a person to function normally, which has won mutual recognition from all three parties.

As a low observable code of conduct, character and moral restrains a doer's every aspect, enabling self discipline and improvement from spiritual, cultural and moral perspectives. For TMU, character and moral is self cultivation of one's inward world and cognitive concept. For the teachers, it is the reliable basis for differentiating people and predicting people's behavior. For the business management, it is the grey area in their staff's behavior which can affect a company's interest and atmosphere.

Science attainment is related to the requirements of TMU in learning ability and achievement. Learning ability can help estimate how quickly and to what extent one can master new knowledge or technology. Research ability is to discern one's potential power and ability of self reflection and exploring the unknown. Professional achievement and interdisciplinary knowledge reflect one's past performance of learning and research ability.

Training students is to serve the society. The requirement for students' professional quality is to help determine how effectively a student can work in the workplace. It is both the ultimate goal of student training and a more representational requirement of professional quality.

\section{B. Summary and Forecast}

The training of TMU is based on its own, and is from the school and for the enterprise. These three aspects are closely linked and interact.

Opinions vary with regard to students' competency education or talent training mode. This research studies and analyzes the competency model for TMU, and proposes some countermeasures and suggestions. However, the subjects investigated are limited to undergraduates. Future research can extend to a similar model targeting at both undergraduates and graduate students or even doctorates, contrast the differences between them, analyze the deepseated reasons and put forward corresponding suggestions.

Although the authors have made substantial field and online investigations for this study, imperfections still remain. The field investigation is limited to several local universities. Regional difference of the online survey is not big enough. Diversity of the sample data is not fully embodied. Yet regional difference is one of the factors that influence higher education (quality of teaching, facility condition and so on). Therefore, further research should diversify regional factors and enhance universality of the model.

\section{ACKNOWLEDGMENTS}

This paper is a part of the outcomes of the following research projects:

2011 Guangdong provincial education science program "An empirical analysis on the training model of compound 
talents in the high end service industry" (Serial number : 2011tjk299)

2015 major bidding project of Shenzhen municipal education science program "Study on the countermeasures of building the first-class tourism management discipline and specialty in Shenzhen special economic zone" (Serial number: ybzz15002)

2016 Guangdong provincial higher education reform project of undergraduate colleges "Research and Practice on the cultivation of innovative talents of high-level university - taking tourism management specialty as an example"

\section{REFERENCES}

[1] D. C. McClelland, "Testing for competence rather than for intelligence," American Psychologist, 1973, 28(1), pp. 1-14.

[2] P. Patanakula and D. Milosevicb, "A competency model for effectiveness in managing multiple projects," Journal of High Technology Management Research, 2008, 29 (18), pp. 118-131.

[3] L. M. Spencer, Competence at Work. John Wiley \& Sons Inc., 1993, 17 (22), pp. 25-32.

[4] M. Mansfield, "Measuring quality in higher education: a competency approach," Quality in Higher Education, 2001, 3 (7), pp. 69-73.

[5] J. F. Peng and X. J. Jin, Design of Employee Competency Model. Beijing: Renmin University of China Press, 2003.

[6] K. Shi, J. C. Wang and C. P. Li, "Research on the evaluation of the competency model of top management," Journal of Psychology, 2002, 6 (3), pp. 27-33.

[7] C. M. Wang and M. K. Chen, "Analysis of management competency: structural equation model test," Science of Psychology, 2002, 9 (1), pp. 513-516.

[8] Q. X. Gu and M. Zhu, "Research on the competency of human resource professionals," Human Resource Development in China, 2001, 10 (10), pp. 4-8.

[9] N. Y. Tang and X. Y. Li, "On the organizational competency based on individual competency," Scientific Economic Society, 2003, 6 (02), pp. 34-38. 